\title{
CONGENITAL HYPOPLASIA OF THE ILIAC ARTERIES
}

\author{
By C. G. Roв, M.C., M.Chir., F.R.C.S., and K. Owen, M.S., F.R.C.S. \\ Surgical Unit, St. Mary's Hospital, London
}

Congenital abnormalities of the major peripheral arteries are uncommon and, although the impression may occasionally be gained that the vessel at the site of an arterial thrombosis is abnormally narrow, there is usually co-existing atheroma and it is difficult to separate cause and effect.

Two patients have now been seen with symptoms of arterial insufficiency in whom arteriograms and inspection of the arteries at operation suggested congenital hypoplasia of the common and internal iliac artery in one patient and of the external iliac artery in the other.

\section{Case I (an engineering fitter, age 4I)}

This patient had a sudden attack of pain and swelling of the left leg and was treated at another hospital with anticoagulants, it being considered that he had a femoral vein thrombosis. His swelling was easily controlled with an elastic stocking, but on walking upstairs he developed pain at the back of the left thigh, relieved by resting. He had no claudication pain on level walking, but always walked slowly. Six months later he developed a small ulcer above the internal malleolus, which remained unhealed.

One year after his first symptom he was seen at St. Mary's Hospital because of his persisting claudication on climbing stairs and his unhealed ulcer.

On examination he was obese (weighing I4 stone). There was slight oedema of his left leg below the knee and he had a shallow ulcer above the internal malleolus, the surrounding skin being purple and oedematous. There were no other nutritional changes. The femoral pulse was very weak and the popliteal and posterior tibial pulses were absent, but a faint dorsalis pedis pulse was palpable.

The right leg was normal and all the pulses were palpable except for the popliteal.

His blood pressure was $120 / 80 \mathrm{~mm}$. He was found to have glycosuria and had a fasting blood sugar of $135 \mathrm{mg}$./100 ml. with a diabetic glucose tolerance curve. His glycosuria was controlled by dieting without insulin. An arteriogram (Fig. I)

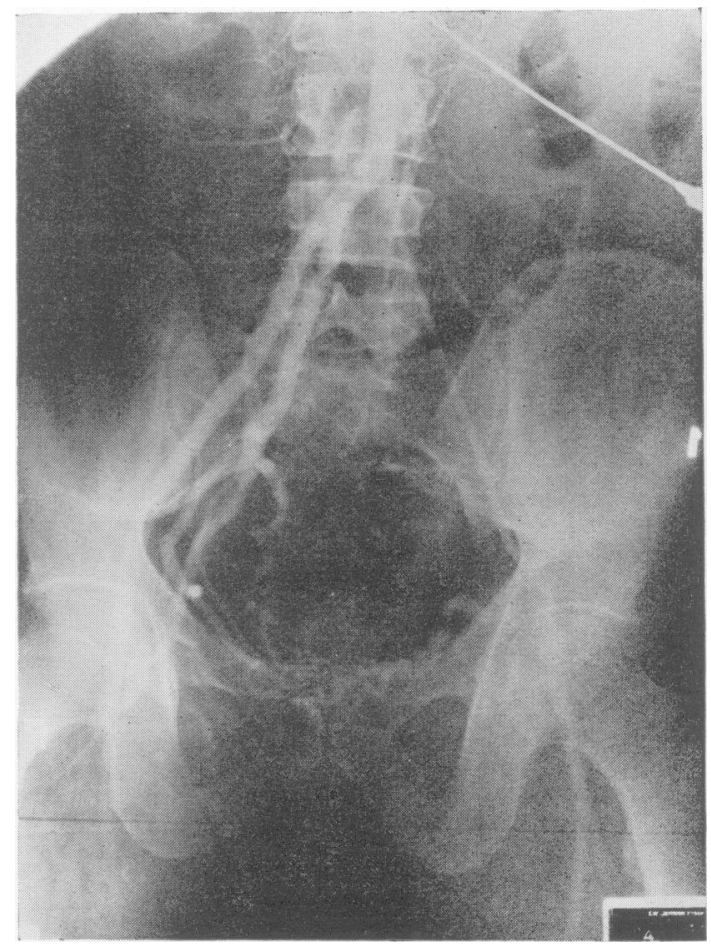

FIG. I.-Hypoplastic left common and external iliac artery (case No. I).

showed the aorta and right iliac vessels to be normal, but on the left side the common iliac and external iliac vessels were represented by an extremely narrow but smooth-walled vessel. The internal iliac artery was absent. A phlebogram showed the femoral and popliteal veins to be replaced by several vessels.

At laparotomy the aortic bifurcation was slightly higher than normal, but the aorta and left iliac artery were otherwise normal with no overt atheroma. The left common and external iliac arteries were extremely narrow, but soft and thinwalled and no atheroma was detectable. The left femoral artery was normal and feebly pulsatile. 
An end-to-side bypass homograft was inserted from the aorta to the femoral artery, but shortly after releasing the clamp it was evident that thrombosis had occurred in the graft. Efforts to obtain a flow were unsuccessful and the graft was therefore removed.

He made a straightforward post-operative recovery and his symptoms were unaltered.

Case 2 (an R.A.F. flight-sergeant, age 46 )

This patient had noticed increasing weakness of the left leg for one year. He was unable to walk further than 150 yards because of this weakness, but had no actual pain. He recovered after resting for a short period and was able to walk a further I 50 yards.

On examination the colour and nutrition of the left leg were good and there was no obvious wasting. All pulses were present in this leg, but they were very weak. The pulses in the right leg were of normal volume. His blood pressure was $120 / 80 \mathrm{~mm}$. There were no other abnormalities on physical examination or laboratory investigation.

An aortogram performed at the R.A.F. Hospital, Ely, showed normal appearances except for an abnormally narrow but smooth external iliac artery.

At laparotomy the aorta, right iliac and left common iliac vessels were of normal calibre, soft and thin-walled with no evidence of atheroma. The left external iliac artery was extremely small, but also soft and thin-walled. The internal iliac artery was present, but also small.

An end-to-side bypass homograft was inserted from the common iliac to the femoral artery, which was normal in every way, the graft being passed under the inguinal ligament. After completing the anastomosis the clamps at both ends of the external iliac were not removed until a good flow had been established through the graft for some minutes. It was thought that this measure might reduce the likelihood of clotting in the graft.

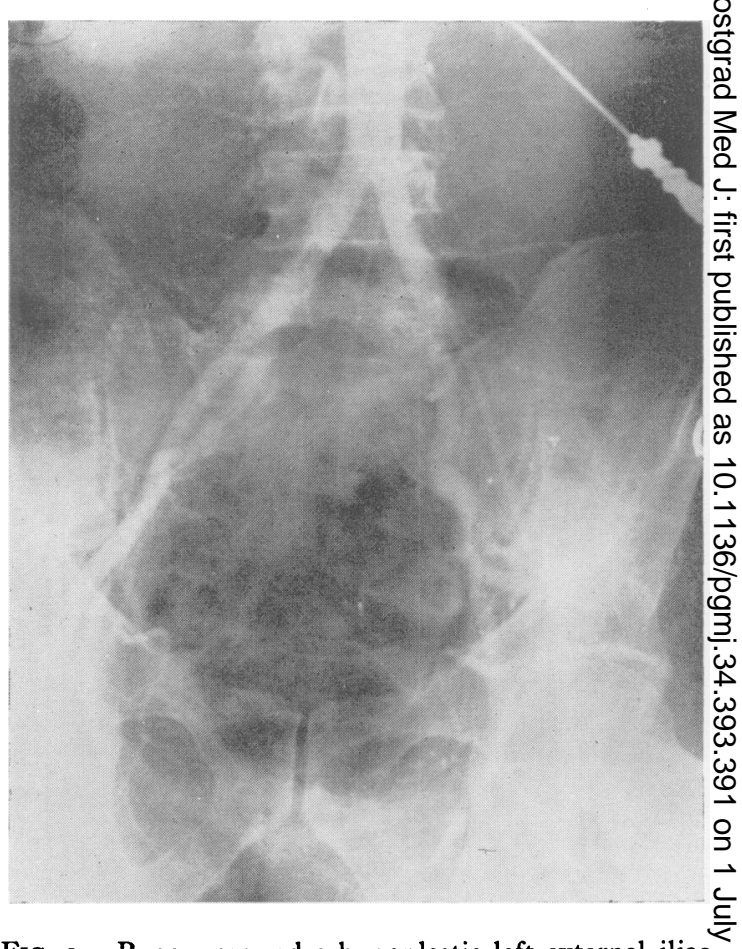

FIG. 2.-Bypass around a hypoplastic left external iliac artery (case No. 2).

Post-operatively he made a straightforwagd recovery and had full ankle pulses. An aortogra (Fig. 2) demonstrated the graft to be functioning well. The narrow external iliac vessel can also be seen in this picture.

When seen two months after operation he was able to walk an unlimited distance.

In both these patients the arteriographic appearances and the operation findings suggested that the iliac arteries were congenitally hypoplastic. It was not felt justifiable to remove a section of the 3 vessel for histology.

Bibliography continued from page 390-Y. H. Mitchell, M.B., Ch.B., D.Obst., R.C.O.G. BIBLIOGRAPHY

AGOSTAS, W. N., REEVES, N., SHANKS, E. D., and SYDENSTRICKER, V. P.'(1952), New Engl. $\mathcal{F}$. Med., 246, 217.

ASHBY, D. W., and LAZAR, T. (I95I), Lancet i, 1091.

CALDWELL, W. G. D. (1953), Lancet i, I 127.

CAMPBELL, C. H. (1955), Med. F. Austr. 26, 941.

CLARK, D. H. (1953), Lancet i, I255.

COMMISSION ON ACUTE RESPIRATORY DISEASES (1946), Arch. intern. Med. 78, 687.

CONWAY, H. (1956), Personal communication.

COOPER, E. E. (1955), Tex. St. F. Med. 51, 6, 308.

COPE, C. L. (1956), Practitioner 175, 1049, 537

DAVIES, D. M. (1953), Lancet i, 1126.

DRESNER, E. (1949), Lancet ii, 1036.

EPSTEIN (1947), Arch. Derm. Syph., 56, I91.

FINLAND, M. (1948), Amer. F. Med. 4, 473.

FISHMAN, H. C. (I95 I), Calif. Med. 74, 392.

GOLDFARB, A. A. (1946), F. Pediat. 28, 579.

GRANT, P. W. (1953), Lancet i, 1129 .

Von HEBRA, F. (1860), 'Handbuch der Speziellen Pathologie,'

Von HEBRA, F. (1866), 'On Diseases of the Skin' (London).

HOWARD, J. E., \& PEDVIS, S. (1 948), Amer. F. Dis. Child. 75, 695.

HUMPHREY, J. A. H. (1955), Brit. Med. F. i, I 32 I.

JONES, I. (I95I), Lancet i, 1280 .

Lancet (1951), ii, 532.

LIBRACH, I. M. (I955), Postgrad. med. F., 31, 361, 570.

MAURIELLO, D. A. (1954), Amer. F. Med., 156, 1495.

PATZ, A. (I947), New Engl. '尹. Med. 236, 697. Hundred Years.'

Hundred Years.'
REITER, H. (I916), Dtsch. med.Wschr., 42, 1535.
ROBINSON, H. M., and McCRUMB, F. R. (1950), Arch. Derm. N Syph., 6r, 539.

ROMER, C. (1953), Brit. Med. F., i, 768 .

ROSENBERG, L., and ROSENBERG', J. (1940), Arch. Derm. Syph.

41, 1066.

NEDDON, I. B. (1947), Brit. Med. F., i, 925.

SNEDDON, I. B. (1953), Lancet, i, 1255 .

SOMMERVILLE, J. (1957), Personal communication.

STEIGMAN, A. J., and KELLY, J. J. (I952), Lancet, i, 875.

THOMAS, B. A. (1950), Brit. Med. F., i, I393.

TODD, R. M. (1953), Med. Illust., 7, 746.

(1953), New E'ıgl. F. Med., 248, 806 . 